\title{
Improving care in Care Homes: what can Primary Care Networks learn from the Vanguards?
}

DOI:

10.1108/JICA-06-2020-0037

\section{Document Version}

Accepted author manuscript

Link to publication record in Manchester Research Explorer

\section{Citation for published version (APA):}

Coleman, A., Croke, S., \& Checkland, K. (2020). Improving care in Care Homes: what can Primary Care Networks learn from the Vanguards? Journal of Integrated Care. https://doi.org/10.1108/JICA-06-2020-0037

\section{Published in:}

Journal of Integrated Care

\section{Citing this paper}

Please note that where the full-text provided on Manchester Research Explorer is the Author Accepted Manuscript or Proof version this may differ from the final Published version. If citing, it is advised that you check and use the publisher's definitive version.

\section{General rights}

Copyright and moral rights for the publications made accessible in the Research Explorer are retained by the authors and/or other copyright owners and it is a condition of accessing publications that users recognise and abide by the legal requirements associated with these rights.

\section{Takedown policy}

If you believe that this document breaches copyright please refer to the University of Manchester's Takedown Procedures [http://man.ac.uk/04Y6Bo] or contact uml.scholarlycommunications@manchester.ac.uk providing relevant details, so we can investigate your claim.

\section{OPEN ACCESS}




\title{
Improving care in Care Homes: what can Primary Care Networks learn from the Vanguards?
}

\author{
Dr Anna Coleman, Dr Sarah Croke \& Prof Kath Checkland \\ The Centre for Primary Care and Health Services Research, University of Manchester.
}

Keywords: Care Homes; Vanguards; Primary Care Networks; integrated care; Policy implementation; New Care Models

\section{Abstract \\ Purpose}

We trace the evolution of a new integrated care policy in the English NHS (enhanced health care in care homes, $\mathrm{EHCH}$ ) from pilot model to wider roll out, over a 4 year period, into the circumstances of COVID-19.

\section{Design/methodology/approach}

Using published evidence and official documentation we compared and contrasted the original $\mathrm{EHCH}$ model/framework, subsequent draft specifications and the final proposals, ahead of implementation.

\section{Findings}

The Primary Care Network EHCH service specification has clearly arisen from the Vanguard programme; however problems related to GP contracts and COVID-19 means, at least initially, there is likely to be some variability over who will be responsible for delivery. It is unknown whether this service, delivered at pace in the current circumstances, will achieve or affect the outcomes envisaged by the pilots.

\section{Originality}

This paper reveals the fragility of health and care policymaking in the current climate. From initial concept, through development and testing, into forced early roll out, our observations reflect the unique impact of a global pandemic shock.

\section{Research limitations/implications}

This is our interpretation of the developing policy for enhanced health care in care homes, which requires further follow up research. We are beginning our final fieldwork phase in Summer 2020, to report on the Vanguard legacy.

\section{Practical implications}

Evaluations of policy success/failure should consider the context and the differing power relations that are present and may impact subsequent take-up and roll-out across the system. We recommend a longitudinal approach to enable a holistic view of policy implementation.

\section{Introduction}

In recent years, there has been an international drive for greater integrated care with the trend towards inter-organisational collaboration (Grone et al., 2001), set against a context that healthcare systems worldwide are extremely complex (Raus et al., 2020). Drivers for this change have included 
rapidly changing demographics of populations (ageing) and economic considerations. "Integrated care", however, is a concept that has been defined in many different ways and a review (Armitage et al., 2009) identified 175 different definitions of integrated care, ranging from outcomes-based (e.g. extent to which care is user or patient-centred) to process-based (e.g. based on what inputs/processes are enacted to achieve goals). For Governments in many countries, developing and implementing policies that promote such collaborations is a policy priority (Mur-Veerman et al., 2008), with a focus on integration as a means to improve patient care and make best use of the resources available (funding, staff etc). Previous work that has examined integrated and multidisciplinary care in care homes (MacNeil, Vroomen et al, 2012) and links to primary care (Gage et al, 2012) has suggested that quality of care can be improved, even without significant clinical effects, but at a higher cost. Cook et al, (2017) identify developing a sustainable framework and approach to integration as key challenges for policy implementation.

The aspiration for better integration of care has been articulated in many different ways both within the UK National Health Service (NHS) and between the NHS and other sectors. In the 1960s this was usually expressed as 'multidisciplinary care', in the 1970s the term 'partnership working' was used and in the 1980/90s 'shared care' was a popular expression (Shaw et al., 2011). Thus, what we now term 'integrated care' has long roots, and covers diverse initiatives which look to address fragmentation, but that differ in underlying scope and values (Stein and Rieder, 2009).

According to (Hughes, 2017) concerns about the cost and complexity of the NHS and social services has led to various integrated care initiatives as a long standing policy response by successive UK Governments. Couple this with an ageing population and integrated care for the more elderly population also becomes increasingly important.

In England, the publication of the Five Year Forward View (NHSE, 2014) introduced one such initiative - the New Care Models (Vanguard) programme which aimed to design and develop new ways of working locally to tackle the deep-seated problems facing the health and care system. The programme invited individual organisations and partnerships to apply to become 'Vanguards' in order to co-design and test new care models. Fifty areas were chosen and each Vanguard was to take a lead in developing new ways of working to "act as the blueprints for the NHS moving forward" (NHSE, 2015 p.3), sharing best practice to be spread and scaled across the country (Checkland et al, 2019).

Our national evaluation of the New Care Models (Vanguard) programme (2017-2021), funded by the NIHR Policy Research Programme, investigated the effects of the Vanguard programme on local healthcare systems, including its local organisations, wider partnerships and service users. Our findings to date, alongside some overall perceptions of the programme's achievements have been published elsewhere (Billings et al., 2019; Checkland et al., 2019; Wilson et al., 2019; Coleman et al., 2020; Checkland et al., in press). This paper traces the journey of the Enhanced Health in Care Homes (EHCH) model, one of the five care models proposed under the Vanguard Programme 2016, from initial proposal to national roll-out via Primary Care Networks (due during 2020).

In 2020 a new contract for providing primary care services in England (NHSE/BMA, 2020) proposed that General Practitioners join local networks which would be responsible for the roll out of specific aspects of the Vanguard programme and specifically the EHCH model. This included a detailed service specification to improve health and care in Care Homes. In this paper we use our understanding of the programme derived both from study of policy documents and our qualitative case study research to reflect on the original policy that supported the development of the EHCH Vanguard model and consider what can be learned from the Vanguard experience to support EHCH 
provision across these Primary Care Networks (PCNs). This is currently a fast changing policy area, with COVID-19, bringing new and unplanned challenges for PCNs. Whilst most service requirements associated with PCNs have been paused to take account of COVID-related pressures, the crisis in Care Homes prompted NHSE/I to require Clinical Commissioning Groups to roll out some elements of the EHCH policy early (May rather than October (Serle, 2020a)) to provide additional support. It is as yet unclear how far this has been achieved, or the extent to which PCNs have been involved.

\section{The New Care Models (Vanguard) programme}

The New Care Models Vanguard programme was a multifaceted, multi-layered integrated care programme for the English NHS. First set out in the NHS Five Year Forward View (NHSE, 2014), it required local action to establish new integrated ways of working, underpinned by a national and regional support programme. The objective was to develop and test new ways of working, with the ultimate goal of wider roll out of new care models, supported by the production of 'standard approaches and products' and 'replicable frameworks' (NHSE, 2015 pp.4-5). Five types of Vanguard were established: Multispecialty Community Providers (MCPs); Primary and Acute Care Systems (PACS); Enhanced Health in Care Homes (EHCH); Urgent and Emergency Care networks (UEC); and Acute Care Collaborations (ACCs).

At its' outset, the Vanguard programme emphasised the bottom-up development of locally designed, new models of care (NHSE, 2016). This permissive approach was welcomed by those involved, and contributed to the high levels of enthusiasm across the programme (Checkland et al., 2019).

It was anticipated that successful local delivery would lead to national spread which, alongside the national support programme, would bring together lessons learned into a definitive service specification to be rolled out more generally. However, in practice this proved difficult, as neither MCPs or PACs generated any clear 'models' of service that could be widely replicated (Checkland et al., 2019). The Enhanced Health in Care Home (EHCH) Vanguards, by contrast, did generate a 'framework', published by NHS England (NHSE, 2016), which will now form the basis for the new approach to providing medical and other care in Care Homes, delivered by Primary Care Networks.

\section{Primary Care Networks}

'Investment and evolution: A five-year framework for GP contract reform' (BMA/NHSE, 2019) set out a number of reforms including the creation of Primary Care Networks (PCNs) across England with minimum entitlements for general practice to support the development of PCNs. PCNs are a cornerstone of the new GP contract framework and consist of groups of general practices working together with a range of local providers - including primary care, community services, social care and the voluntary sector - intended to offer more personalised, coordinated care to their local populations (NHSE/NHSI, 2019). They are intended to "dissolve the historic divide between primary and community health services" (BMA/NHSE, 2019 p.25). It is important to note that PCNs are about provision not commissioning, and are not new organisations. They typically cover populations of 3050,000 people (based on GP registered lists), with individual practices in a local area entering into a network contract as an extension (via a Direct Enhanced Service DES) to the existing contract. Networks are eligible for a number of additional funding streams, including a new 'shared savings' scheme to enable them to benefit from actions to reduce avoidable A\&E attendances, admissions and delayed discharge, streamlining patient pathways to reduce avoidable outpatient visits and overmedication through pharmacist review (NHSE, 2019 pp.14-15). Funds are also available for PCNs to employ clinical professionals who are intended to contribute towards reducing GP workload. The PCN contract was introduced 1 July 2019 (NHS Digital, 2020) and from April 2020 collaboration with 
other local care organisations was to be a formal requirement of Network Agreements, however the purpose and functions of PCNs are still evolving (NHS Confed/NHS Providers, 2019).

\section{NHS Long Term Plan and Care Homes}

The NHS Long Term Plan (NHSE, 2019) was a document published by NHS England which sets out its priorities for healthcare over the next 10 years and shows how the NHS funding settlement will be used. It set out detailed and specific support to be delivered by PCNs to all care home residents by 2023/24, a direct legacy of the EHCH Vanguards. These proposals revealed a change in approach from bottom-up permissive development to top-down prescriptions of policy for care and support, to be delivered to national standards to achieve national targets:

- All care homes to be supported by a consistent team of healthcare professionals, including named general practice support;

- Ensure individuals are supported to have good oral health, stay well hydrated and wellnourished and that they are supported by therapists and other professionals in rehabilitating when they have been unwell;

- Care home residents will get regular clinical pharmacist-led medicine reviews where needed;

- PCNs will also work with emergency services to provide emergency support, including where advice or support is needed out of hours;

- Support for easier, secure, sharing of information between care homes and NHS staff;

- Care home staff will have access to NHSmail, enabling effective secure communication with NHS teams involved in the care of their patient.

NHS England (NHSE, 2019 p.15) argue that EHCH Vanguards have: "shown how to improve services and outcomes for people living in care homes and those who require support to live independently in the community". There is some evidence that $\mathrm{EHCH}$ Vanguards managed to reduce the number of emergency admissions from Care Homes (Wolters et al., 2019), however there is no published evidence about other outcomes, or about which of the many initiatives put in place by Vanguards drove this positive effect.

Learning from the EHCH Vanguards also suggests that "truly collaborative commissioning involves shared system leadership and the development of a shared culture of working and trust at operational level, regardless of the formal health and local authority commissioning structures that are in place" (NHSE/NHSI, 2020a p.23). We additionally highlighted that indicators against which success of Vanguards were measured became progressively limited over time (e.g. bed days, A\&E attendances) and no longer considered the local objectives that initiatives were originally developed to address (Checkland et al., 2019).

\section{Proposed EHCH specification}

According to NHS England/NHS Improvement (NHSE/NHSI, 2019) "the New Care Models programme [which ran between 2015-18] developed and tested the Enhanced Health in Care Homes (EHCH) Framework to improve health and care provision for people living in care homes" (ibid p.14). It was claimed that this Framework drew "on evidence from [...] evaluations of the New Care Models to design the service requirements" (ibid p.15). The EHCH Vanguard Framework was published on the NHS England website (NHSE, 2016) and the draft contract and specification for PCNs (including delivering EHCH elements) was published in December 2019 (NHSE/NHSI, 2019).

The initial PCN EHCH service model focused on national roll out of the first four clinical elements of the EHCH framework: enhanced primary care support; multidisciplinary team support; reablement 
and rehabilitation; and high-quality end-of-life care and dementia care for everyone living permanently in care homes (residential and nursing). In contrast to the original Vanguard policy, which also included people in supported living environments or who were at high risk of losing their independence and was permissive with a focus upon local innovation, the PCN service specification was highly detailed and prescriptive. The initial draft (BMA/NHSE, 2019) was quickly rejected by the British Medical Association (BMA) and by GPs, due in part to 'high and unambiguous levels of concern' around workforce, resources, specificity and perceived performance management (NHSE/BMA, 2020 p.40). GPs were particularly concerned that under the original specification they would have been responsible for providing training to Care Home staff. Following negotiations, the draft was replaced by a new offer to GPs (NHSE/BMA, 2020), reducing the number of new services to be introduced in 2020/21 from five to three. The EHCH specification remained, with scaled back requirements, reducing the frequency with which GPs or community geriatricians were expected to visit care home patients and providing a more flexible approach to medical input. The introduction of an additional payment ( $£ 120$ per bed/year) will also be introduced from September 2020, ensuring that PCNs with more Care Homes in their area have the resources they need. This offer was further rejected by a symbolic vote of BMA Local Medical Committee representatives (March 2020), indicating ongoing concerns (Serle, 2020b), however this vote does not affect the roll out of the contract. Concerns are ongoing as some GP practices and their associated PCNs struggle to commit to delivering the EHCH specifications by the deadlines specified (Norton, 2020).

The following table shows the main areas of divergence/development, which the policy has made, along its journey from the original EHCH framework (NHSE, 2016) to the current EHCH framework V2 (NHSE/NHSI, 2020a) in terms of care model, service approach, joined up working, workforce, IT data and technology.

\section{Table I. Comparing the EHCH framework to current proposals}

Comparing the proposed EHCH elements of this contract offer to the Vanguard 'model' reveals this policy has experienced some interesting modifications along its journey, most notably that the latest guidance features the greatest number of elements, including some which had been rejected during the middle stages. Key elements of: enhanced primary care support for Care Homes; multidisciplinary team support; a focus on enablement and rehabilitation; and high quality end-of-life care and dementia care have all translated from the Vanguard framework into the new specifications. Further important aspects of the original EHCH Vanguard framework (NHSE, 2016), such as access to a consistent, named GP (linked to a wider primary care team), data sharing and training, have also been maintained. Interestingly, the elements of joined-up commissioning and collaboration between health and social care; workforce development; and data, IT and technology proposed within the Vanguard framework, that appeared to lose their former prominence within the draft $\mathrm{EHCH}$ proposals (NHSE/NHSI, 2019), regained this within the updated EHCH Framework Version 2 released in response to calls for a rapid increase in support for Care Homes during the COVID-19 pandemic (NHSE/NHSI, 2020a).

A further distinction is that EHCH Vanguards were, in general, established and led by Clinical Commissioning Groups (CCGs), in collaboration with Local Authorities and GPs. A lack of clarity over responsibilities meant that each of the $6 \mathrm{EHCH}$ Vanguards established their own local arrangements for co-operation between GPs, community nursing services, social care and the CCG, with the role of 
GPs both variable and locally determined (Checkland et al., in press). In the new PCN model, by contrast, responsibilities are clearer with the GP-led Network responsible for establishing and facilitating the required collaborative arrangements. It remains to be seen whether this is a strength or a weakness. Clarity may be useful in establishing who is responsible for what, but a highly determined service specification does not necessarily allow the new services to build upon existing local relationships and alliances.

The urgent situation surrounding the global pandemic SARS-CoV-2/COVID-19, and the impact on Care Homes, has prompted NHSE/NHSI to rethink this approach, yet again, bringing forward some elements of the EHCH model immediately "to be established as part of the COVID-19 response by CCGs, working with general practice, community services providers, care homes, local medical and pharmacy committees and wider partners in their area" (NHSE/NHSI, 2020b p.1) and additional elements/amendments not previously trialled. CCGs are now advised to assume responsibility where PCNs are currently not able to take this forward, although "The intention is that from 1st October, the model will be adapted to support the service specification already set out in the Network Contract Directed Enhanced Service" (NHSE/NHSI, 2020b p.2).

In new Guidance initially issued in May 2020 by DHSC (live document, DHSC, 2020), additional operational and clinical support is promised in the form of:

- Training in infection control, with CCG infection control nurses "training the trainers" in care homes on the recommended approach to infection prevention control, personal protection equipment (PPE) usage and testing advice;

- Distributing additional PPE to Local Resilience Forums, which care homes should be able to draw on if they have urgent shortages;

- Infection control fund to help providers pay for additional staff and /or maintain the normal wages of staff who, in order to reduce the spread of infection, need to reduce the number of establishments in which they work, reduce the number of hours they work, or self-isolate;

- All patients being discharged to care homes will be tested prior to discharge;

- Ensuring there is sufficient alternative accommodation to quarantine and isolate residents, if needed, before returning to their care home from hospital, with costs of providing this accommodation covered by $f 1.3$ billion COVID-19 discharge funding via the NHS;

- A SAGE sub-group focusing specifically on the scientific issues affecting care homes and residents in care homes; alongside a hub of best practice to develop practical tools for care home staff;

- Timely access to clinical advice for care home staff and residents, including a named clinical lead for every care home and weekly check-ins;

- Proactive support for people living in care homes, including through personalised care and support planning as appropriate;

- Support for care home residents with suspected or confirmed COVID-19 through remote monitoring (and face-to-face assessment where clinically appropriate) by a multidisciplinary team where practically possible (including those for whom monitoring is needed following discharge from either an acute or step-down bed);

- Sensitive and collaborative decisions around hospital admissions for care home residents if they are likely to benefit;

- Community health improvement teams are also working with primary care and NHSX to roll out video consultations within care homes. 
In addition to this support, local authorities are asked to review or put in place a care home support plan, drawing on local resilience and business continuity plans, and submit a planning return setting out a short overview of current activity and the forward plan, by the end of May 2020.

Our research suggests that the 'bottom up' and emergent approach taken under Vanguards was an important element in encouraging change (Checkland et al., 2019; Checkland et al., in press). While we recognise that the current international situation is unprecedented, we suggest that the implementation of prescriptive proposals in the UK for Care Homes, delivered top-down and at pace, risks ignoring some of the most valuable lessons to emerge from the Vanguard programme, notably the value placed by those involved on the scope for local innovation and context-specific service development. A further important lesson from the $\mathrm{EHCH}$ Vanguards is that truly collaborative commissioning involves far more than simply transferring budgets or joint contracting. Rather, it involves shared system leadership and the development of a shared culture of working and trust at operational level, regardless of the formal health and local authority commissioning structures that are in place.

\section{Conclusion}

The moves underpinning the prescription and direction given to PCNs, pre COVID-19, for the roll out of EHCH provision across England (specific deadlines set milestones for 31/07/20, 30/09/20 and $31 / 03 / 21$ ), marked a palpable shift from the permissive, local Vanguard approach. This inevitably raises the question of whether local needs and context will be adequately addressed by the prescriptive service requirements of the $\mathrm{EHCH}$ model rollout. The metrics chosen to measure success in both the short term and longer term, incentivised by an impact fund, will be important, as incentivised activity is likely to be prioritised.

Overlying this, and due to the COVID-19 outbreak as we described, some elements have been brought rapidly forward (to May 2020) for roll out by CCGs. This may further muddy the water in the medium to longer term around who is responsible for delivering what and who should be held accountable, especially when organisations across sectors (NHS, LAs and others) are involved.

Challenges may also arise due to the different footprints covered by CCGs, LMCs, Integrated Care Systems (ICS), community service providers, Local Authorities and PCNs - and while it is possible that a single Community Service Provider may be helpful to establish common approaches across their jurisdiction, it may also be the case that community service providers will need to provide variable approaches. Close co-operation between different providers will be vital.

In summary, whilst the PCN EHCH service specification has clearly arisen out of the Vanguard programme, there is likely to be variability over who will be responsible for delivering this - PCNs or CCGs, at least initially - each bringing important differences which may affect outcomes. Having PCNs as service co-ordinators may be valuable, but it will require significant efforts to ensure good collaboration with other services across broader populations and may be premature, given the immaturity of PCNs which were only established a year ago. Vanguards valued their freedom to innovate and determine their own service design (Checkland et al., 2019), and it will be interesting to see whether a mandated centrally determined service, delivered at pace under most challenging circumstances, can deliver the beneficial outcomes achieved or envisaged by the pilots (Morciano et al, 2020).

There is general agreement internationally, that integration of care is required for effective service delivery to an aging population. However, creating effective policy, its piloting and further rollout, is 
a challenge. It will be interesting to observe how things develop for this policy in the context of a global pandemic. The NHS, like many healthcare systems, has been impacted immeasurably as a result of COVID-19, raising questions for many about the steps for the recovery and future development of healthcare systems. Providing care that is integrated across sectors will be an important component of the ongoing recovery.

Raus et al., (2020) identified challenges faced by policy makers in the drafting of integration policy in a number of countries (UK, Belgium and Norway): conceptual; methodological-empirical; and resource challenges. We have highlighted further challenges related to testing and implementing such policy in our example of EHCH. Specifically, we have highlighted the dangers inherent in an over-centralised, mandated approach to integration, suggesting that policy makers across jurisdictions should recognise and embrace the value that local actors, building upon local relationships and trust, can bring to integration programmes.

\section{References}

Armitage, G. D., Suter, E., Oelke, N.D. and Adair, C.E. (2009) 'Health systems integration: state of the evidence'. International Journal of Integrated Care, Vol. 9 No.2, e82. DOI: 10.5334/ijic.316

Billings, J., Mikelyte, R., Coleman, A., Maclnnes, J., Allen, P., Croke, S. and Checkland, K. (2019) 'Supporting integrated care in practice: Perceptions of a national support programme for the development of New Care Models in England'. Journal of Integrated Care, Vol. 28 No.1, pp.27-40.

British Medical Association/NHS England (2019) 'Investment and evolution: A five-year framework for GP contract reform to implement The NHS Long Term Plan', available at:

https://www.england.nhs.uk/wp-content/uploads/2019/01/gp-contract-2019.pdf (accessed 5th June 2020)

Checkland, K., Coleman, A., Billings, J., Maclnnes, J., Mikelyte, R., Laverty, L. and Allen, P. (2019) 'National evaluation of the Vanguard new care models programme Interim report: understanding the national support programme". University of Manchester, LSHTM and University of Kent.

Checkland, K., Coleman, A., Croke, S., Billings, J., Mikelyte, R., Maclnnnes, J. and Allen, P. (in press) 'National Evaluation of the Vanguard New Care Models Programme: report of qualitative case studies: understanding system change'. University of Manchester, LSHTM and University of Kent.

Coleman, A., Billings, J., Allen, P., Mikelyte, R., Croke, S., Maclnnes, J. and Checkland, K. (2020) 'Ambiguity and Conflict in Policy Implementation: The Case of the New Care Models (Vanguard) Programme in England'. Journal of Social Policy, early cite, available at: http://dx.doi.org/10.1017/S0047279420000082 (accessed 5th June 2020)

Cook, G., McNall, A., Thompson, J., Hodgson, P., Shaw, L. and Cowie, D. (2017) 'Integrated Working for Enhanced Health Care in English Nursing Homes', Journal of Nursing Scholarship, Vol. 49 No.1, pp.15-23, available at: https://sigmapubs-onlinelibrary-wileycom.manchester.idm.oclc.org/doi/pdfdirect/10.1111/jnu.12261 (accessed 27th July 2020)

DHSC (2020) 'Coronavirus (COVID-19): care home support package', available at: https://www.gov.uk/government/publications/coronavirus-covid-19-support-for-carehomes/coronavirus-covid-19-care-home-support-package (accessed 5th June 2020) 
Gage, H., Dickinson, A., Victor, C., Williams, P., Cheynel, J., Davies, S.L., Iliffe, S., Froggatt, K., Martin, W. and Goodman, C. (2012) 'Integrated working between residential care homes and primary care: a survey of care homes in England', BMC Geriatrics, Vol. 12 No.71, pp.1-10, available at:

https://bmcgeriatr.biomedcentral.com/track/pdf/10.1186\%2F1471-2318-12-71 (accessed 27th July 2020)

Gröne, O. and Garcia-Barbero, M. (2001) 'Integrated care: a position paper of the WHO European office for integrated health care services', International Journal of Integrated Care, Vol. 1, pp.1-10.

Hughes, G. (2017) 'New models of care: the policy discourse of integrated care', People, Place and Policy, Vol.11 No.2, pp. 72-89. DOI: 10.3351/ppp.2017.67928677

Mur-Veerman, I., van Raak, A. and Paulus, A. (2008) 'Comparing integrated care policy in Europe: does policy matter?' Health Policy, Vol. 85 No.2, pp.172-183.

MacNeil Vroomen, J.L., Boorsma, M., Bosmans, J.E., Frijters, D.H.M., Nijpels, G. and van Hout, H.P.J. (2012) 'Is It Time for a Change? A Cost-Effectiveness Analysis Comparing a Multidisciplinary Integrated Care Model for Residential Homes to Usual Care', PLoS ONE, Vol. 7 No.5, e37444 pp.1-6. doi:10.1371/journal.pone.0037444 (accessed 27th July 2020)

Morciano, M., Checkland, K., Billings, J., Coleman, A., Stokes, J., Tallack, C. and Sutton, M. (2020) 'New integrated care models in England associated with small reduction in hospital admissions in longer-term: a difference-in-differences analysis', Health Policy, Vol.124 No.8, pp. 826-833 https://doi.org/10.1016/j.healthpol.2020.06.004

NHS Confederation/NHS Providers (2019) 'Primary Care Networks a quiet revolution', available at: https://nhsproviders.org/media/687950/primary-care-networks-a-quiet-revolution.pdf (accessed 5th June 2020)

NHS Digital (2020) 'Primary Care Network Workforce - 31 March 2020', available at: https://digital.nhs.uk/data-and-information/publications/statistical/primary-care-networkworkforce/31-march-2020/background (accessed 5th June 2020)

NHS England (2014) 'Five year Forward View', available at: https://www.england.nhs.uk/wpcontent/uploads/2014/10/5yfv-web.pdf (accessed 5th June 2020)

NHS England (2015) 'The Forward View Into Action: New Care Models: update and initial support', available at: https://www.england.nhs.uk/wp-content/uploads/2015/07/ncm-support-package.pdf (accessed 5th June 2020)

NHS England (2016) 'The framework for enhanced health in care homes', available at: https://www.england.nhs.uk/wp-content/uploads/2016/09/ehch-framework-v2.pdf (accessed 5th June 2020)

NHS England (2019) 'The NHS Long Term Plan', available at: https://www.longtermplan.nhs.uk/wpcontent/uploads/2019/08/nhs-long-term-plan-version-1.2.pdf (accessed 5th June 2020)

NHS England/British Medical Association (2020) 'Update to the GP contract agreement 2020/21 2023/24', available at: https://www.england.nhs.uk/wp-content/uploads/2020/03/update-to-thegp-contract-agreement-v2-updated.pdf (accessed 5th June 2020)

NHS England/NHS Improvement (2019) 'Network Contract Direct Enhanced Service: Draft Outline Service Specifications', available at: https://www.engage.england.nhs.uk/survey/primary-care- 
networks-service-

specifications/supporting_documents/Draft\%20PCN\%20Service\%20Specifications\%20December\%20 2019.pdf (accessed 5th June 2020)

NHS England/NHS Improvement (2020a). 'The Framework for Enhanced Health in Care Homes 2020/21 - Version 2', available at: https://www.england.nhs.uk/wp-content/uploads/2020/03/theframework-for-enhanced-health-in-care-homes-v2-0.pdf (accessed 5th June 2020)

NHS England/NHS Improvement (2020b). 'COVID-19 response: Primary care and community health support care home residents', available at: https://www.england.nhs.uk/coronavirus/wpcontent/uploads/sites/52/2020/03/COVID-19-response-primary-care-and-community-healthsupport-care-home-residents.pdf (accessed 5th June 2020)

Norton, T. (2020) 'Large GP network at risk of collapsing over 'private conversation' row', Health Services Journal 09/06/20, available at: https://www.hsj.co.uk/east-midlands/large-gp-network-atrisk-of-collapsing-over-private-conversation-row/7027807.article (accessed 28th July 2020)

Raus, K., Mortier, E. and Eeckloo, K. (2020) 'Challenges in turning a great idea into great health policy: the case of integrated care'. BMC Health Services Research, Vol. 20 Article number: 130, available at: https://doi.org/10.1186/s12913-020-4950-z (accessed 5th June 2020)

Serle, J. (2020a) 'Contentious NHS scheme to bolster care homes brought forward', Health Services Journal 29/4/20, available at: https://www.hsj.co.uk/contentious-nhs-scheme-to-bolster-carehomes-brought-forward/7027530.article (accessed 28th July 2020)

Serle, J. (2020b) 'GPs vote down 'Trojan horse' PCN scheme' Health Services Journal 11/03/20, available at: https://www.hsj.co.uk/service-design/gps-vote-down-trojan-horse-pcnscheme/7027109.article (accessed 5th June 2020)

Shaw, S., Rosen, R. and Rumbold, B. (2011) 'An over view of Integrated care in the NHS: What is integrated care?' Nuffield Trust, available at: https://www.nuffieldtrust.org.uk/files/2017-01/whatis-integrated-care-report-web-final.pdf (accessed 5th June 2020)

Stein, K.V. and Rieder, A. (2009) 'Integrated care at the crossroads - defining the way forward'. International Journal of Integrated Care, Vol. 9 No.2, pp.1-7

Wilson, P., Billings, J., Maclnnes, J., Mikelyte, R., Welch, E., Richie, R., and Checkland, K. (2019) 'Investigating locally commissioned evaluations of the NHS Vanguard programme'. University of Manchester, LSHTM and University of Kent.

Wolters, A., Santos, F., Lloyd, T., Lilburne, C. and Steventon, A. (2019) 'Emergency admissions to hospital from care homes: how often and what for?' Health Foundation, available at: https://www.health.org.uk/publications/reports/emergency-admissions-to-hospital-from-carehomes (accessed 5th June 2020) 